\title{
The Use of Moringa Leaves Extract as a Plant Growth Hormone on Cowpea (Vigna Anguiculata)
}

\author{
Hasan Muhammad Maishanu ${ }^{1}$, Muhammad Murtala Mainasara ${ }^{2}$, Sanusi Yahaya ${ }^{1}$, Audu Yunusa $^{3}$ \\ ${ }^{1}$ Usmanu Danfodiyo University \\ P. M. B. 2346, Sokoto, Nigeria \\ ${ }^{2}$ Universiti Tun Hussein Onn Malaysia \\ 101 Beg Berkunci, Parit Raja, Batu Pahat, Johor, 86400, Malaysia \\ ${ }^{3}$ Ibrahim Badamasi Babangida University Lapai \\ KM3, Minna Road, Lapai, Nigeria
}

DOI: $10.22178 /$ pos.29-4

LCC Subject Category:

S1-(972)

Received 28.11.2017

Accepted 15.12.2017

Published online 31.12.2017

Corresponding Author:

Muhammad Murtala Mainasara

mmgusau96@gmail.com

(c) 2017 The Authors. This

article is licensed under a

Creative Commons Attribution

4.0 License

\begin{abstract}
The use of Moringa oleifera leaves extract as plant growth hormone on cowpea plant (Vigna unguiculata) has been studied at the biological garden of Usmanu Danfodiyo university, Sokoto. An extract was made by grinding young moringa leaves and diluted with water at the ratio of 1:30 $25 \mathrm{mls}$, three blocks were made labelled $M, F$ and $D$, with three replications each, the extract prepared was applied on block ' $M$ ' only, while a small pinch of synthetic fertilizer (Urea) was applied in block ' $F$ ' and a control treatment was set up using distilled water, which applied to each plant in hill $D$. results indicates that in the $3^{\text {rd }}$ week of observation the cowpea plants treated with moringa extract have the highest mean of stems, number of leaves and branches, length of leaves and branches, and thickness of stem. Then followed by those treated fertilizer mean and finally those treated with distilled water this result shows that moringa leaves extract has an improving effects on the growth of cowpea. Moringa leaf extract (MLE) is rich with numerous growth hormones, particularly zeatin that has been reported to increase the crops yield in the range of 10 $45 \%$. Moringa leaf juice also contains micronutrients in sufficient quantities and suitable proportions that increase the growth, yield components and yield of a variety of crops.
\end{abstract}

Keywords: Moringa oleifera; cowpea; extract; Vigna ungucuilata.

\section{INTRODUCTION}

Cowpea is an important grain legume found mainly in the savannah regions of sub-Saharan Africa, where it is grown in intercropping system with cereals such as millets and sorghum. This indigenous crop to sub-Saharan Africa thrives relatively better than other crops in the droughtprone areas of the region. The average grain yield of cowpea in the region is estimated to be about $470 \mathrm{~kg} / \mathrm{ha}$ [9] and the potential yield are up to $2.3 \mathrm{t} / \mathrm{ha}$. Nigeria and Niger Republic are the two highest cowpea producers worldwide at 3.04 million and 0.69 million tons with average yield of 0.69 and $0.17 \mathrm{t} / \mathrm{ha}$, respectively. Cowpea is grown primarily for human consumption of the grains, which are rich in protein, carbohydrates and contain some minerals as well. In many homes in sub-Saharan Africa, cowpea, be- ing a legume, is a major source of dietary protein [4]. Cowpea is cultivated for its immature pods and mature seeds and is consumed extensively in Africa and, to a lesser extent, in Asia [15].

Plant hormones can be used to increase yield per unit area because they influence every phase of plant growth and development. Traditionally, there are five groups of growth regulators which are listed: auxins, gibberellins, abscisic acid, ethylene and cytokinins [7]. Cytokinins enhance food production. Zeatin is one form of the most common forms of naturally occurring cytokinin in plants. Fresh Moringa oleifera leaves have been shown to have high zeatin content. Moringa leaves gathered from various parts of the world were found to have high zeatin concentrations of between $5 \mathrm{mcg}$ and $200 \mathrm{mcg} / \mathrm{g}$ of leaves [7, 6, 12, 3]. 
The dependency on the use of inorganic fertilizers as a source of plant nutrients by farmers and their high cost is further associated with land and soil degradation and environmental pollution. Thus, there is continuous need to search for alternative safe natural sources of plant nutrients [12]. Moringa oleifera is one of such alternative, being investigated to ascertain its effect on growth and yield of crops and thus can be promoted among farmers as a possible supplement or substitute to inorganic fertilizers. Moreover, several re-searches have indicated that $M$. oleifera Lam (family: Moringaceae) is a highly valued plant with multipurpose effects. Moringa oleifera as a novel natural biostimulant for plant growth, could play a role in improving drought tolerance in plants under saline condition $[1,11]$. The tree ranges in height from 5 to $10 \mathrm{~m}$. It is found wild and cultivated in many countries of the tropics and subtropics $[12,3]$.

\section{MATERIALS AND SAMPLE USED}

Young leaves / branches of moringa were harvested from young full grown trees located at a small village named Tudun Wada close to the main campus of Usmanu Danfodiyo University, Sokoto, distilled water was collected from the energy research center, Usmanu Danfodiyo University, Sokoto, the cowpea seeds (Vigna unguiculata) were bought from the Sokoto Agricultural Rural Development Agency (SARDA), and the fertilizer (Urea) used was bought from the Sokoto state central market.

\section{Preparation of Moring Leave Extract (MLE)}

For preparation of MLE, leaf extraction was performed according to Price (2007) as cited in (Yasmeen, 2011), by grinding young shoots (leaves and tender branches) of not more than 40 days old with a pinch of water $(1 \mathrm{~L} / 10 \mathrm{~kg}$ fresh material) in a locally fabricated extraction machine. After sieving through of the extract were prepared with distilled water then used in experiments for priming as well as foliar spray [17]. The extraction use to be carried out a day to its application and kept in the refrigerator to avoid from being contaminated by some harmful microorganism and other unfavourable environmental conditions.

\section{Construction of the nursery beds and sowing of the cowpea seeds (Vigna anguiculata)}

A portion of biological science garden with sufficient supply of sunlight was cleared using hoe, cutlass, shovel, rake etc and three block nursery beds were constructed. Three hills (ridges) of one feet interval were constructed in each of the above constructed block nursery beds. Three cowpea seeds are sown per hole in the constructed hills spacing to $25 \mathrm{~cm}$ that is the space between one hole and another is 25 $\mathrm{cm}$. The germination was monitored for one week after the date of sowing. When all the seeds germinated they were thinned to one.

\section{Labeling of the constructed hills (ridges) and application of treatments}

The constructed hills were labeled appropriately that is those to be treated with moringa extract as "M", synthetics fertilizer as " $F$ " and distilled water as "D". Five seedling in each hill (ridges) were measured after three days. The above prepared treatments were appropriately applied that is $25 \mathrm{mls}$ of moringa extract to each seedling of the hills labeled $M$, small pinch of fertilizer (Urea) to those labeled $\mathrm{F}$ and distilled water those labeled D.

\section{Measurement and observation}

The plants were watered every day with tap water in the biological sciences garden and the measurement of the following growth parameters were taken every week on five plants of each hill. The lengths of stems, leaves, branches (cm) number of leaves and branches as well as thickness of stems. The dry and fresh weights of the plants were measured and recorded using weighting balance in the mycology lab.

\section{RESULTS AND DISCUSSIONS}

\section{Treatments}

Three types of treatments were practiced.

1. Treatment with moringa leaves extract

2. Treatment with fertilizer (urea)

3. Treatment with distilled water (control)

After the collection of sample, germination studies were carried out in September, 2012 in the biological sciences garden of Usmanu Dan- 
fodiyo University, Sokoto. The results of the treatments observed from three weeks and the parameters recorded were statistically analyzed and presented as shown in Figures 1 to 6.

In Figure 1 shown above, first week cowpea treated with fertilizer have the highest means length of stem of $12.7 \mathrm{~cm}$, followed by those treated with moringa leaves extract with 11.2 $\mathrm{cm}$, and finally, those treated with distilled water with $8.71 \mathrm{~cm}$.

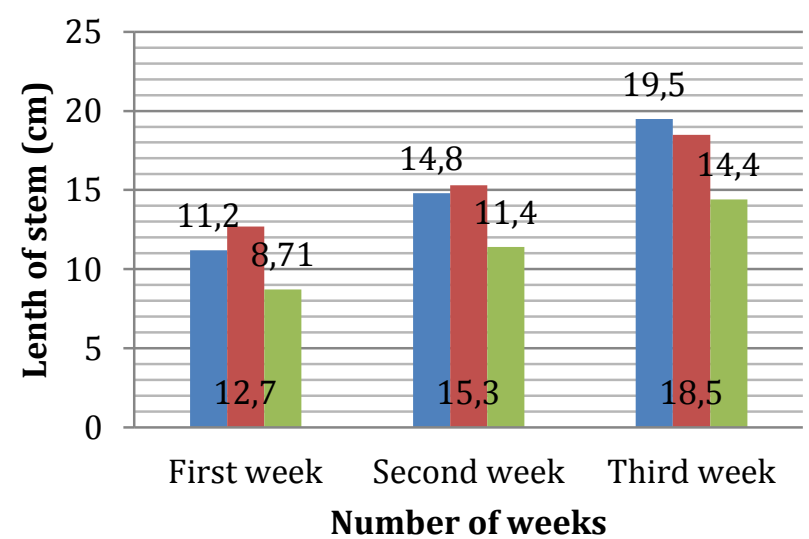

Moringa extract $\square$ Fertilizer $\square$ Distilled water

Figure 1 - Number of stem

In the second week cowpea treated with fertilizer also have the highest mean length of stems; of 15.3 followed by those treated with moringa leaves extract with $14.8 \mathrm{~cm}$ and finally, by those treated with distilled water has $14.4 \mathrm{~cm}$.

In Figure 2, first week cowpea plants treated with fertilizer have the highest mean number of leaves; 8.9 followed by those treated with moringa leaves extract with 8.3 and finally, by those treated distilled having water with 3.87.

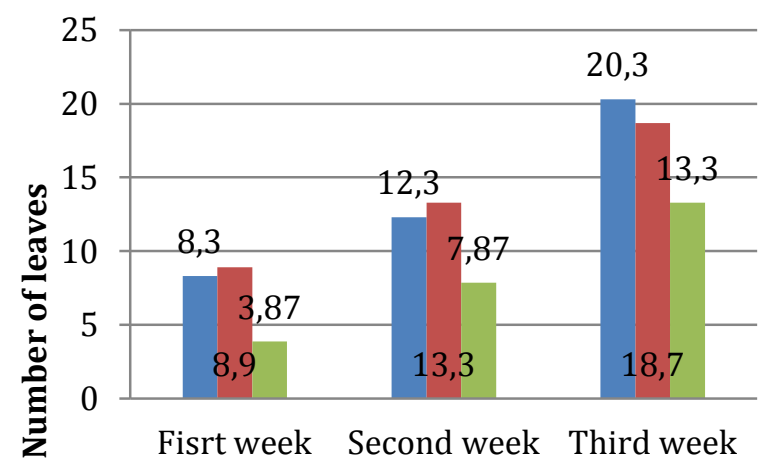

Number of weeks

$\square$ Moringa Extract $\square$ Fertilizer $\square$ Distilled water

Figure 2 - Number of leaves
In the second week, those treated with fertilizer also have the highest mean number of leaves; 13.3, followed by those treated with moringa leaves extract having 12.3 and finally, by those treated with distilled water with 7.87. In the third week, those treated with moringa leaves extract have the highest mean number of leaves with 20.3; followed by those treated with fertilizer with 18.7 and finally, those treated with distilled water have 13.3.

In Figure 3 shown above, first week the cowpea plants treated with fertilizer have the highest mean length of leaves of $6.1 \mathrm{~cm}$, followed by those treated with moringa extract with $5.2 \mathrm{~cm}$ and finally, by those treated distilled water have $3.8 \mathrm{~cm}$.

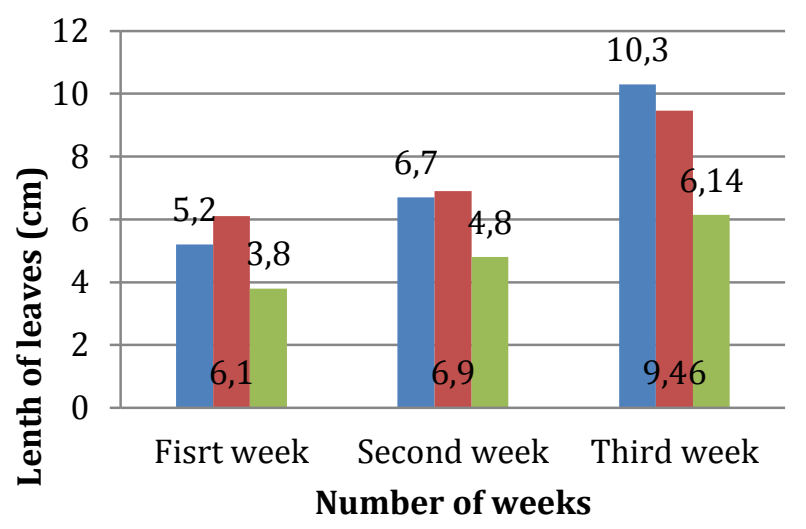

$\square$ Moringa extract $\square$ Fertilizer $\square$ Distilled water

Figure 3 - Length of leaves

In the second week, those treated with fertilizer also have the highest mean length of leaves with $6.9 \mathrm{~cm}$, followed by those with moringa leaves with $6.7 \mathrm{~cm}$ and finally by those with distilled water have $4.8 \mathrm{~cm}$.

In the third week, those treated with moringa leaves have highest mean length of leaves with $10.3 \mathrm{~cm}$, followed by those treated with fertilizer with $9.46 \mathrm{~cm}$ and finally those treated with distilled having $6.14 \mathrm{~cm}$.

The Figure 4 shows, first week the cowpea treated with fertilizer have the highest mean number of branches with 2.86, followed by those treated with moringa leaves extract with 2.13 and no branch was observed in those treated with distilled water.

In the second week, those with fertilizer also have the highest mean leaves of branches with 
3.91, followed by those treated with moringa leave extract with 3.81 and finally by those treated with distilled water have 2.13.

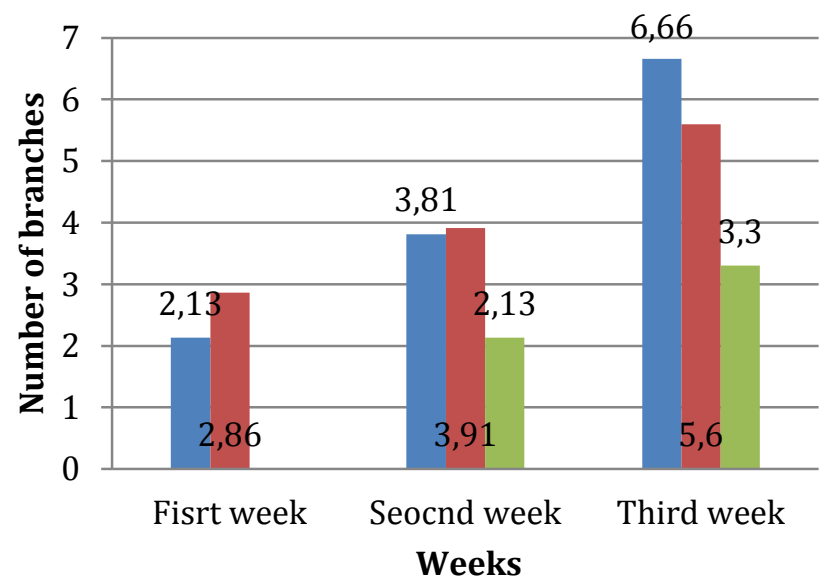

$\square$ Moringa Extract $\square$ Fertilizer $\square$ Distilled water

Figure 4 - Number of branches

In the third week, those with moringa leaves extract have the highest mean number of branches with 6.66 , followed by those treated with fertilizer; 5.61 and finally by those treated with distilled water having 3.50 .

The Figure 5 shows, first week the cowpea treated with fertilizer have the highest mean length of branches with $6.19 \mathrm{~cm}$ followed by those treated with moringa leaves extract having 4.95, and no branches in those treated with distilled water.

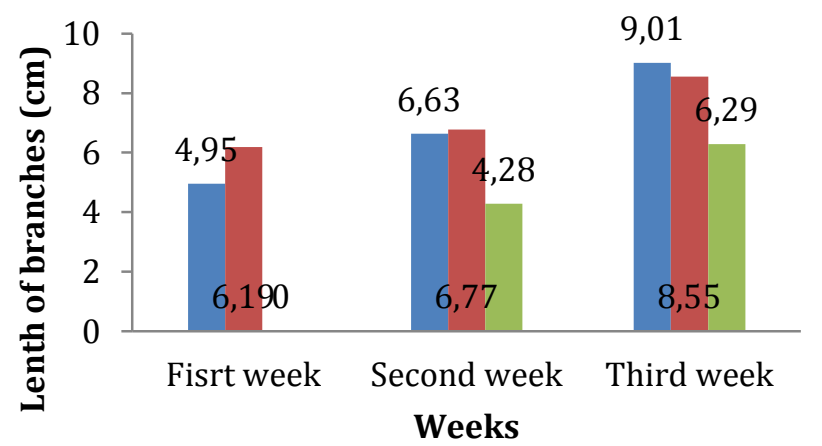

$\square$ Moringa extract $\square$ Fertilizer $\square$ Distilled water

Figure 5 - Length of the branches

In the second week, those treated with fertilizer also have the highest mean length of branches with 6.77 , followed by those treated with moringa leaves extract with 6.63 and finally, by those treated with distilled water having 4.28. In the third week, those treated with moringa leaves extract have the highest mean length of branches with $9.01 \mathrm{~cm}$, followed by those treated with fertilizer with $8.55 \mathrm{~cm}$ and finally by those treated with distilled water having $6.29 \mathrm{~cm}$.

The Figure 6 shown above, first week the cowpea treated with fertilizer have the highest mean thickness of stems with 1.01, followed by those treated with moringa leaves extract with 1.0 , and finally, by those treated with distilled water having 0.89 .

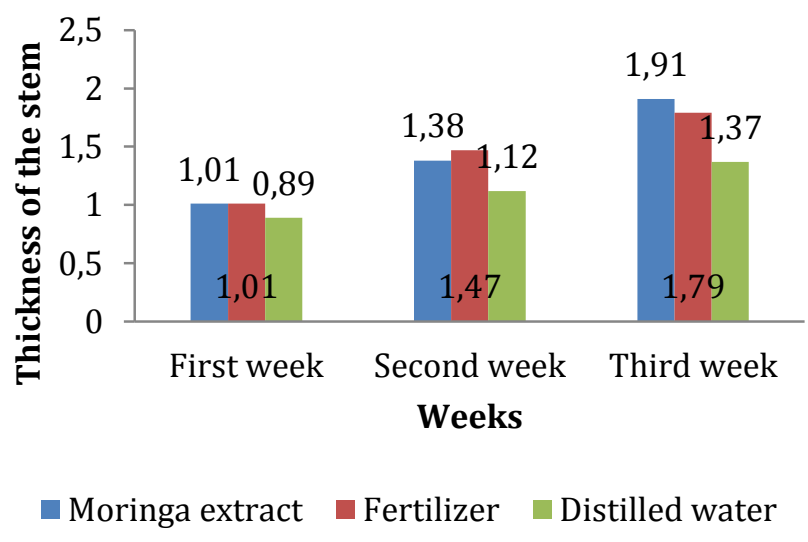

Figure 6 - Thickness of the stem

In the second week, those treated with fertilizer have the highest mean thickness of stems with 1.47 , followed by those treated with moringa leaves extract 1.38, and finally by those treated with distilled water having 1.12. In the third week, those treated with moringa leave extract are having the highest mean thickness of stems 1.91, followed by those treated with fertilizer with 1.79 and finally by those treated with distilled water having the lowest mean thickness of stems with 1.37.

Plant growth hormones are chemicals that effect flowering aging, root growth, distortion and killing of leaves, stems and other parts preventing of leafing or leaf ,fall and many other conditions [7, 16]. Hormones are produced naturally by plants, while plant growth regulators are applied to plant by human. Applied concentration of these substances usually measures in part per-million (ppm) and in some cases in part per billion (ppb). These growth regulating substances are applied as a 
liquid, drench to soil around a plant base. They may need to be re-applied in order to achieve the desire effect [7].

Plant extracts of some trees and crop residues have been reported to influence crop growth and yield. Leaf extract of M. oleifera is one such example. It has been reported that foliar application of $M$. oleifera leaf extract accelerated growth of tomato, peanut, corn and wheat at early vegetative growth stage, improve resistance to pests and diseases and enhanced more and larger fruits and generally increase yield by 20 to $35 \%$ [5]. In this study, the application of moringa leaf extract has also effectively improved seed germination and seedling vigour as compared to untreated control. L. Fuglie [10] reported yield enhancement by 25-30 \% in onions, bell pepper, soya, maize, sorghum, coffee, tea, chili, melon by moringa leaf extract application. He suggested that this growth and yield enhancement was due to presence of zeatin, a cytokinin in moringa leaves.

In another study with Abelmoschus esculentus reported that Application of moringa leaf extract reduced soil bulk density and increased soil organic matter (OM), N, P, K, Ca, Mg, growth and yield of okra compared with the control [2]. Similarly in another research by [13] on Kinnow' mandarin (Citrus nobilis L. $\times$ Citrus deliciosa T.) Reported that leaf nitrogen $(\mathrm{N})$, phosphorous $(\mathrm{P})$, $\mathrm{K}$, calcium (Ca), manganese (Mn) and $\mathrm{Zn}$ were significantly increased with all treatments. C. Phiri [14] also reports that M. oleifera leaf extracts enhanced germination of sorghum by $29 \%$, increased length of hypocotyls of wheat by $14.9 \%$.

\section{CONCLUSION}

Natural plant growth biostimulants are intensively used nowadays for plant growing in normal and adverse conditions. $M$. oleifera is one of the novel natural biostimulant for plant growth, that play an important role in improving yields nutritional quality and tolerance in plants under adverse condition. MLE increases growth and yields of cowpea. From the results of the field experiments, it may be concluded the higher the frequency of moringa application, the greater the increase in plant height, dry matter and yield of the crop.

\section{REFERENCES}

1. Abd El-Mageed, T. A., Semida, W. M., \& Rady, M. M. (2017). Moringa leaf extract as biostimulant improves water use efficiency, physio-biochemical attributes of squash plants under deficit irrigation. Agricultural Water Management, 193, 46-54. doi: 10.1016/j.agwat.2017.08.004

2. Adekiya, A. O., Agbede, T. M., Aboyeji, C. M., Dunsin, O., \& Ugbe, J. O. (2017). Green manures and NPK fertilizer effects on soil properties, growth, yield, mineral and vitamin C composition of okra (Abelmoschus esculentus (L.) Moench). Journal of the Saudi Society of Agricultural Sciences. doi: 10.1016/j.jssas.2017.05.005

3. Basra, S., Iftikhar, M., \& Afzal, I. (2011). Potential of moringa (Moringa oleifera) leaf extract as priming agent for hybrid maize seeds. International Journal of Agriculture and Biology, 13(6), 1006-1010.

4. Boukar, O., Massawe, F., Muranaka, S., Franco, J., Maziya-Dixon, B., Singh, B., \& Fatokun, C. (2011). Evaluation of cowpea germplasm lines for protein and mineral concentrations in grains. Plant Genetic Resources, 9(04), 515-522. doi: 10.1017/s1479262111000815

5. Culver, M., Fanuel, T., \& Chiteka, A. (2012). Effect of Moringa extract on growth and yield of tomato. Greener Journal of Agricultural Sciences, 2(5), 207-211.

6. Davies, P. (2015). Plant hormones and their role in plant growth and development. N. d.: Milton Keynes.

7. Davies, P. (Ed.). (2010). Plant Hormones: Biosynthesis, Signal Transduction, Action! N. d.: Springer.

8. Davies, P. J. (1987). The Plant Hormones: Their Nature, Occurrence, and Functions. Plant Hormones and Their Role. In Plant Growth and Development (pp. 1-11). doi: 10.1007/978-94-009-35853_1 
9. Ericksen, P., Ingram, J., \& Liverman, D. (2010). Food security and global environmental change. London: Earthscan.

10. Fuglie, L. (1999). The miracle tree: Moringa oleifera, natural nutrition for the tropics. New York: Church World Service.

11. Howladar, S. M. (2014). A novel Moringa oleifera leaf extract can mitigate the stress effects of salinity and cadmium in bean (Phaseolus vulgaris L.) plants. Ecotoxicology and Environmental Safety, 100, 69-75. doi: 10.1016/j.ecoenv.2013.11.022

12. Mona, M. A. (2013). The potential of Moringa oleifera extract as a biostimulant in enhancing the growth, biochemical and hormonal contents in rocket (Eruca vesicaria subsp. sativa) plants. International Journal of Plant Physiology and Biochemistry, 5(3), 42-49. doi: 10.5897/ijppb2012.026

13. Nasir, M., Khan, A. S., Basra, S. M. A., \& Malik, A. U. (2016). Foliar application of moringa leaf extract, potassium and zinc influence yield and fruit quality of "Kinnow" mandarin. Scientia Horticulturae, 210, 227-235. doi: 10.1016/j.scienta.2016.07.032

14. Phiri, C. (2010). Influence of Moringa oleifera leaf extracts on germination and early seedling development of major cereals. Agriculture and Biology Journal of North America, 1(5), 774-777. doi: 10.5251/abjna.2010.1.5.774.777

15. Sreerama, Y. N., Sashikala, V. B., Pratape, V. M., \& Singh, V. (2012). Nutrients and antinutrients in cowpea and horse gram flours in comparison to chickpea flour: Evaluation of their flour functionality. Food Chemistry, 131(2), 462-468. doi: 10.1016/j.foodchem.2011.09.008

16. Taiz, L., Zeiger, E., Moller, I., \& Murphy, A. (2015). Plant physiology and development (6th ed.). Sunderland: Sinauer.

17. Yasmeen, A. (2011). Exploring the potential of moringa (Moringa oleifera) leaf extract as natural plant growth enhancer (Doctoral dissertation; University of Agriculture, Faisalabad, Pakistan). Retrieved from http://docplayer.net/21758964-Exploring-the-potential-of-moringa-moringaoleifera-leaf-extract-as-natural-plant-growth-enhancer.html 